\title{
Short Communication: Presence of arbuscular mycorrhiza in maize plantation land cultivated with traditional and improved land management
}

\author{
LILY ISHAQ \\ Faculty of Agriculture, Universitas Nusa Cendana. Jl. Adisucipto, Penfui, Kota Kupang 85001, East Nusa Tenggara, Indonesia. Tel.: +62-380-881085, \\ email: lily.ishaq@yahoo.com
}

Manuscript received: 9 May 2017. Revision accepted: 31 May 2018.

\begin{abstract}
Ishaq L. 2018. Short Communication: Presence of arbuscular mycorrhiza in maize plantation land cultivated with traditional and improved land management.Trop Drylands 2: 20-24. Arbuscular mycorrhizas (AM) are one of the key functional soil biota that can greatly contribute to crop productivity and agricultural sustainability. Their presence could be influenced by soil conditions, such as land management, and the sporulation of the fungal forming mycorrhiza could be affected by season, i.e., rainy, and dry seasons. Previously, it was found that the abundance of AM fungi was higher under maize cropping with traditional land management (no-tillage, no input of agrochemicals) than that under maize cropping system with more modern land management (tillage, agrochemical input), when the soils were sampled at rainy season. As the presence of AM fungi could be influenced by climate factors i.e., rain/season, the present study was carried out to examine the abundance and diversity of AM fungi in maize plantation land cultivated with traditional and improved land management in the dry season. At each land management system, three locations of study were purposively selected, and at each location within the cropping system, three soil samples were collected. A total of 9 soil samples representing each land management system were evaluated. The variables observed included AM fungal spore density (expressed as the number of AM fungal spores per $100 \mathrm{~g}$ of soil) and biodiversity of AM fungi (expressed as relative abundance of AM fungal spore). It was found that the density of AM fungal spores under a maize cropping system with traditional land management was 203.55 per $100 \mathrm{~g}$, whereas only 84.91 spores per 100 $\mathrm{g}$ soil were found under a maize cropping system with improved land management, supporting the previous findings. Despite only six AM,0 fungal spores morphotypes were observed under maize plantation land of both traditional and improved land management, the abundance of the morphotype was different between the two land management systems. The study needs to be extended at a broader location and time to get more representative information on the impact of land management on the abundance of AM fungi in tropical agriculture.
\end{abstract}

Keywords: Arbuscular mycorrhizal fungi, spore density, relative abundance, maize, land management

\section{INTRODUCTION}

Maize is an important economic crop in East Nusa Tenggara. There are two types of land management commonly practiced by local farmers for maize production in the region, namely traditional and improved land management. At the traditional land management, farmer usually grows maize without any inputs of agrochemicals and tillage is not practiced on the land, whereas on the improved land management, farmers tillage the land before planting and commonly apply agrochemicals including inorganic fertilizer and pesticide to increase maize productivity. As the land management between these two types of maize cropping systems is different, it is likely that the impact it may have on the soil condition, particularly on soil beneficial microorganisms such as arbuscular mycorrhizal fungi possibly be different.

Arbuscular mycorrhiza (AM), a mutualistic symbiosis between fungi and higher plants, is one of the most ubiquitous soil beneficial organisms. Mycorrhizal fungi have multiple ecological functions including improving the absorption of mineral nutrients and water to their host plants (Smith and Read 2008), enhancing plant resistance to pathogens (Song et al. 2015), improving plants tolerance to environmental stresses such as drought, salinity and heavy metals (Porcel and Ruiz-Lozzano 2004; Gohre and Paszkowski 2006; Kaya et al. 2009), and maintaining soil structure in agricultural soils that is important for land sustainability (Jeffries et al. 2003).

There are some factors that might influence the association between mycorrhizas and their host plants such as fungi forming mycorrhizas, plants/host, and environmental conditions (Smith and Read 2008). Environmental conditions could affect population, diversity, and distribution of AM fungi (Brundrett 1991; Sieverding 1991). For example, climate and edaphic factors, and physicochemical edaphic factors have been related to sporulation and colonization of AM fungi (de Oliveira and de Oliveira 2010; Panwar et al. 2011). In agricultural ecosystem, in particular, the population and diversity of AM have been reported to be influenced by land management (Sieverding 1991; Ezawa et al. 2000; Oehl et al. 2003; Kabir 2005).

Previously, a study on the abundance of AM associated with corn planted with traditional and more modern farming system in Kupang District East Nusa Tenggara 
Timur, found that the spore density of AM under a more modern farming system was lower than those found under a traditional farming system (Ishaq et al. 2017). Since AM fungal colonization and spore numbers could be influenced by season (rainfall) (de Oliveira and de Oliveira 2010), the current study extended the previous study, when was conducted in rainy season, to be repeated in dry season. The present study, therefore, was aimed to evaluate the presence of AM fungi in the land of maize cropping system with traditional and improved land management systems in the dry season.

\section{MATERIALS AND METHODS}

\section{Study location}

East Nusa Tenggara, Indonesia is a semi-arid region with a 3-4 month rainy season (December-March/April) and 8-9 months dry season. The average annual rainfall ranges between 1250-1500 mm per year. In Kupang District, the soils are calcareous that are rich in base cations mainly calcium and magnesium, but commonly low in nitrogen and available phosphorus.

Soil samples were collected from the land where maize is grown with both traditional and improved land management. The term "improved land management" is used just to emphasize that tillage and agrochemical inputs (inorganic fertilizer and pesticides) are applied in the farming system. In both farming systems (traditional and improved land management), planting mainly depends on rain as water source. due to unavailability of the irrigation system to support the farming systems.

Soil samples were collected in the dry season of November 2015. During the dry season, no crops were cultivated including maize due to water limitation. Previously, the soil was sampled around the rhizosphere of maize in the presence of maize as the AM host plant. Whereas in the present study, the soil was sampled in the absence of the host plants. It was possible to evaluate the presence of AM in the study area in the absence of maize as the main host of AM. This is because the roots of the host plant were not removed from below ground when harvest. In each type of land management, soils were sampled at three different locations (each type of land management consisted of three different locations; 6 locations in total). For the land where maize is usually cultivated with improved land management, soil samples were collected from Noelbaki, Baumata and Tarus Villages, whilst for the land where maize is grown with traditional land management; soil samples were collected from Kolhua, Sikumana and Noelbaki Villages. Before sampling the soil, survey and interviews were conducted to obtain information on land management. At each location, soil samples were diagonally taken. Soil samples were collected around the plant at a depth of $0-20 \mathrm{~cm}$. The sampling position was plotted using GPS coordinates, and the other nearby vegetation (other than maize) was recorded. Spore extraction was conducted at the Laboratory of Microbiology of Agricultural Faculty of Nusa Cendana University, Kupang, Indonesia.

\section{Extraction of AM fungi spores}

Spores of AM fungi were extracted from soil samples using wet-sieving and sucrose based on the methods described by Brundrett et al. (1996). Briefly, soils samples $(100 \mathrm{~g})$ were suspended in $500 \mathrm{ml}$ water, stirred for $7 \mathrm{mins}$, and decanted through 500, 250, 150 and $45 \mu \mathrm{m}$ sieves. This washing and decanting process was repeated until the water was clear. Soils filtered on fine screens (250, 150 and 45 $\mu \mathrm{m})$ were transferred into a $50 \mathrm{ml}$ tube, and then centrifuged for 5 mins at $2500 \mathrm{rpm}$ to remove organic matter. The supernatant and floating debris were discarded, and the pellets were resuspended in $60 \%$ sucrose then centrifuged again for 2 mins at $2500 \mathrm{rpm}$ to separate spores from the denser soil components. The spores in the supernatant were placed on $45 \mu \mathrm{m}$ and washed with water to remove the sucrose. The spores were transferred on a Buchner funnel underlined with Whatman paper (No. 41). The spores were collected and counted under a compound microscope. For biodiversity calculation, the spores were grouped into morphotypes based on spore appearance (color, size, surface of the spore and sub-tending hyphae).

\section{Observation and data analysis}

Data of spore density were $\log (\mathrm{x}+1)$ transformed before being analyzed. The data was analyzed using Nested (Hierarchy) Analysis of Variance design where the locations of study were nested within the land management factor. AM fungal spores were isolated and then counted manually under a compound microscope (Leica Galen III). Broken spores were not included in the isolation process and calculation. The spores were grouped into morphotypes based on criteria as described above. Spore density was expressed as the number of spores in $100 \mathrm{~g}$ soil, whilst biodiversity was measured as relative abundance. Relative abundance was expressed as percentage of spore number of a morphotype in each site over total spore in each site.

\section{RESULTS AND DISCUSSION}

Nested ANOVA analyses showed that the location within each cropping system where the soil samples were collected had no significant effect on the spore density of AM fungi. At the three locations of maize cropping system with traditional land management, the average AM fungal spore density found in location 1 (Kolhua) was 7.0. That was not significantly different from AM fungal spore density found at location 2 (Sikumana) and location 3 (Noelbaki) with 6.63 and 6.66 spores per $100 \mathrm{~g}$ soil, respectively [(data were $\log (\mathrm{X}+1)$ transformed)]. Similar findings were also observed at the three locations where maize was grown with improved land management. The average spore density found in location 1 (Baumata) was 4.67 spores per $100 \mathrm{~g}$ soil; that was not significantly different from AM fungal spore density found in location 2 (Noelbaki) and location 3 (Mata Air) with 5.81 and 6.24 spores per $100 \mathrm{~g}$ soil, respectively [(data were $\log (\mathrm{X}+1)$ transformed)].

On the other hand, when comparing the spore density of AM fungi between the two types of land managements 
(traditional and improved land management systems) the result of nested analysis showed that AM spore density between the two land management systems was significantly different. The spore density of AM fungi in soil samples taken from the land where maize is cultivated with traditional land management was significantly higher $(\mathrm{P}<0.05)$ than the spore density of AM fungi found in soil samples taken from the land where maize is cultivated with improved land management. The spore density of AM fungi in soils sampled from maize plantation land cultivated with traditional land management was 2.25 [(log $(\mathrm{X}+1)$ transformed)] spores per $100 \mathrm{~g}$ soil), whilst only 1.6 spores $[(\log (\mathrm{X}+1)$ transformed $)]$ per $100 \mathrm{~g}$ soil of $\mathrm{AM}$ fungi were found in soil sample taken from maize plantation land cultivated with improved land management (Figure 1).

When comparing the density of AM fungi observed at the current study with that of the previous study (Ishaq et al. 2017), it was discovered that the number of AM fungal spores found in this study tended to be higher than the previous study, both under traditional and improved land management systems. In the previous study (Ishaq et al. 2017), the averages of spore density at traditional and more modern maize cropping system were 88.53 and 43.1, respectively. The averages of AM spore density under maize cropping systems in the present study are respectively, 203.7 and 84.9 spore/100 $\mathrm{g}$ soil for traditional and improved land management.

Six types of AM fungal spore morphotypes were found in this study at each land management, namely yellow, black, orange, white, rough yellow surface, and reddish color. The relative abundance of the morphotypes found in this study is described in Table 1, whilst examples of the morphotypes are illustrated in Figure 2. Although all the six morphotypes were observed at both traditional and improved land management systems, the relative abundance of the morphotype was different between the two land management systems. Morphotype 4 (white) was more abundant in the soil taken from the maize cropping system with traditional land management, contributed to $51.36 \%$ of the total morphotypes observed. This was followed by morphotype 1 (yellow) with $25.03 \%$. Whereas soil taken from maize plantation land cultivated with improved land management, morphotype 6 (reddish) was dominant and accounted for $45.4 \%$ of the total morphotypes observed, followed by morphotype 1 (yellow) with $18.8 \%$.

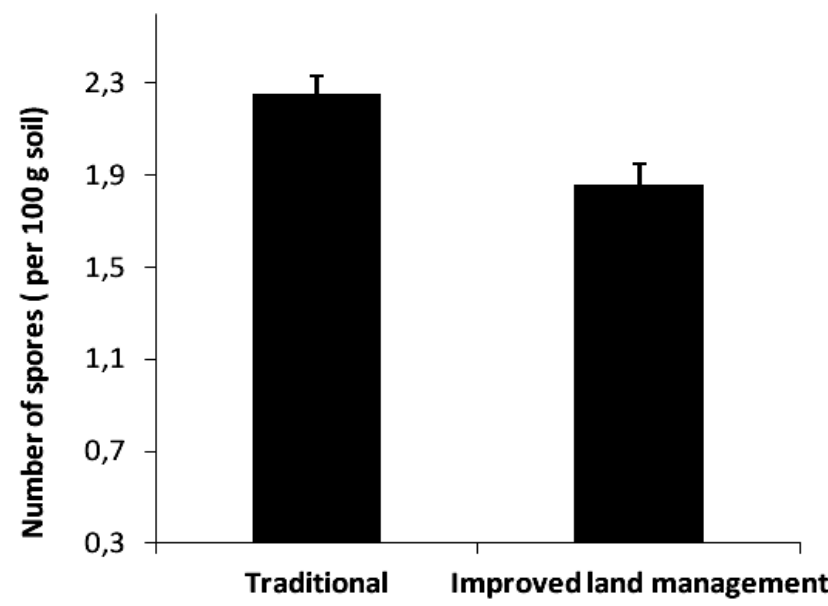

Figure 1. Spore density of AM fungi in soil sampled from the land where maize is cultivated with traditional and improved land management. Values are means $(n=9) \pm$ SE. Data were $\log (X+1)$ transformed

Table 1. Spore density of morphotype and the relative abundance (RA) of the morphotype found under maize cropping system with traditional (A1, A2 and A3) and improved land management (B1, B2 and B3). A is the total of A1, A2 and A3, and B is the total of B1, $\mathrm{B} 2$ and $\mathrm{B} 3$

\begin{tabular}{|c|c|c|c|c|c|c|c|c|c|c|c|c|}
\hline Morphotype & A1 & $\mathbf{R A}$ & $\mathbf{A 2}$ & $\mathbf{R A}$ & $\mathbf{A 3}$ & $\mathbf{R A}$ & B1 & $\mathbf{R A}$ & B2 & $\mathbf{R A}$ & B3 & $\mathbf{R A}$ \\
\hline 1 (Yellow) & 112 & 14.04 & 227 & 45.77 & 121 & 22.24 & 25 & 22.9 & 38 & 13.4 & 81 & 21.83 \\
\hline 2 (Black) & 16 & 2.0 & 1 & 0.202 & 31 & 5.69 & 5 & 4.59 & 27 & 9.51 & 27 & 7.278 \\
\hline 3 (Orange) & 48 & 6.01 & 1 & 0.202 & 56 & 10.29 & 9 & 8.26 & 13 & 4.58 & 91 & 24.53 \\
\hline 4 (White) & 530 & 66.42 & 200 & 40.32 & 214 & 39.33 & 2 & 1.83 & 0 & 0 & 86 & 23.18 \\
\hline 5 (Yellow rough surface) & 0 & 0 & 7 & 1.41 & 9 & 1.65 & 7 & 6.42 & 6 & 2.11 & 0 & 0 \\
\hline 6 (Reddish) & 92 & 11.53 & 60 & 12.1 & 113 & 20.77 & 61 & 56 & 200 & 70.4 & 86 & 23.18 \\
\hline \multirow[t]{2}{*}{ Total } & 798 & 100 & 496 & 100 & 544 & 100 & 109 & 100 & 284 & 100 & 371 & 100 \\
\hline & \multicolumn{6}{|c|}{ Traditional land management } & \multicolumn{6}{|c|}{ Improved land management } \\
\hline Morphotype & \multicolumn{3}{|c|}{$\mathbf{A}$} & \multicolumn{3}{|c|}{ RA $(\%)$} & \multicolumn{3}{|c|}{ B } & \multicolumn{3}{|c|}{$\mathbf{R A}(\%)$} \\
\hline Yellow & \multicolumn{3}{|c|}{460} & \multicolumn{3}{|c|}{25.03} & \multicolumn{3}{|c|}{144} & \multicolumn{3}{|c|}{18.8} \\
\hline Black & \multicolumn{3}{|c|}{48} & \multicolumn{3}{|c|}{2.61} & \multicolumn{3}{|c|}{59} & \multicolumn{3}{|c|}{7.72} \\
\hline Orange & \multicolumn{3}{|c|}{105} & \multicolumn{3}{|c|}{5.71} & \multicolumn{3}{|c|}{113} & \multicolumn{3}{|c|}{14.8} \\
\hline White & \multicolumn{3}{|c|}{944} & \multicolumn{3}{|c|}{51.36} & \multicolumn{3}{|c|}{88} & \multicolumn{3}{|c|}{11.5} \\
\hline Yellow (rough surface) & \multicolumn{3}{|c|}{16} & \multicolumn{3}{|c|}{0.87} & \multicolumn{3}{|c|}{13} & \multicolumn{3}{|c|}{1.7} \\
\hline Reddish & \multicolumn{3}{|c|}{265} & \multicolumn{3}{|c|}{14.42} & \multicolumn{3}{|c|}{347} & \multicolumn{3}{|c|}{45.4} \\
\hline Total & \multicolumn{3}{|c|}{1838} & \multicolumn{3}{|c|}{100} & \multicolumn{3}{|c|}{764} & & 100 & \\
\hline
\end{tabular}




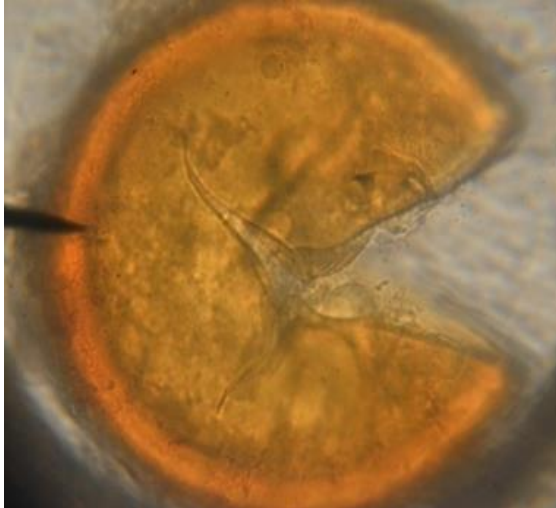

$\mathbf{A}$

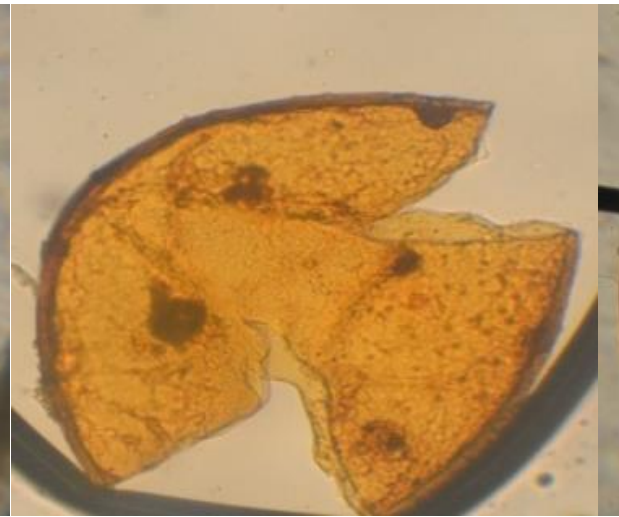

B

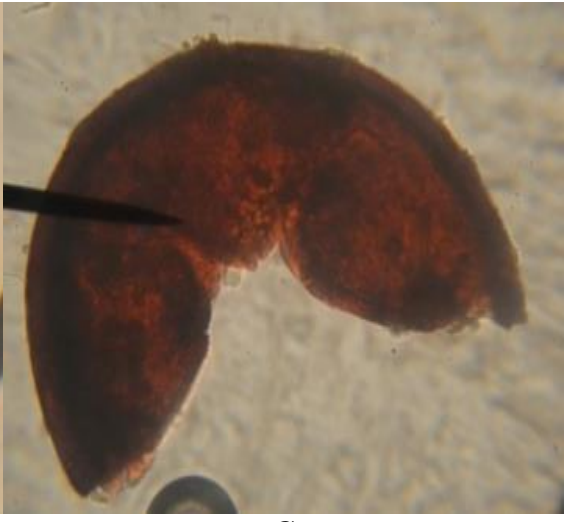

$\mathbf{C}$

Figure 2. Examples of morphotype found; A. Morphotype 1 (yellow, round, 124.32-365.97 $\mu \mathrm{m}$ ), B. Morphotype 5 (rough yellow surface, round, 142.33-302.23 $\mu \mathrm{m}$ ), and C. Morphotype 6 (reddish, round, 144.83-384.43 $\mu \mathrm{m}$ )

This study found that the spore density of AM fungi was affected by land management. The spore density in the soil taken from maize plantation cultivated with traditional land management, was higher than that found in the soil taken from maize plantation with improved land management. The result was consistent with what was previously found under these two cropping systems (Ishaq et al. 2017). The effect of land management on AM sporulation has also been reported by other authors (Oehl et al. 2003, 2010; Schalamuk and Cabello 2010). Many factors can influence distribution and community structure of AM fungi such as climatic and edaphic factors, spatial and temporal variations, vegetation, disturbance, and sporulation ability of AM fungal taxa (Dandan and Zhiwei 2007). Soil disturbances such as tillage (Entry et al. 2002; Kabir 2005; Schalamuk and Cabello 2010), long-term use of inorganic fertilizer (Rubio et al. 2003; Bhadalung et al. 2005), and pesticides (Entry et al. 2002) have been reported to have a negative impact on AM communities. However, other soil factors, such as: soil type and land use intensity (Oehl et al. 2010), physicochemical edaphic properties (Panwar et al. 2011) and climate factors (de Oliveira and de Oleivera 2010), may also determine the sporulation or composition of AM fungal communities. In this study, the lower AM fungal spore density found under the maize cropping system with improved land management, might be related to soil factors such as soil disturbance, agrochemical inputs and soil organic carbon. However, the sporulation might be also related to ability of AM fungal taxa to sporulate at certain times and conditions.

When comparing the density of AM fungi observed in the current study, with the result observed previously (Ishaq et al. 2017), the number of AM fungal spores observed in this current study tended to be higher in both traditional and more modern land management as compared to the previous findings. The higher AM spore density found in this study might be related to climatic and edaphic factors. Previously, the soil samples were collected at the end of rainy season when the soil moisture was still high. The AM types that are sensitive to high moisture might have not been able to sporulate at that time of soil sampling. In this study, the soil samples were collected in dry season when the soil moisture was low, possibly the soil conditions were more favorable for those of highmoisture sensitive types of AM to sporulate resulting in more abundance of spore observed. Furthermore, the fungal species observed may be active at a specific time/condition, being capable of colonizing and multiplying themselves.

Related to diversity of AM fungi, it seemed that the number of AM fungal morphotypes found was not quite distinct between the two land management systems, in which only six morphotypes were observed. The result would be plausible as the main host for AM observation in the study was the same (maize crops). The similar morphotypes found under these two land management systems may also indicate that these morphotypes are general AM colonizers for maize as host plants.

Despite only a small number of morphotypes found in the study, interestingly, the dominance of the morphotype was different between the two land management systems. Morphotype 4 (white) was a dominant colonizer under maize cropping system with traditional land management, whereas morphotype 6 (reddish) was a dominant colonizer under maize cropping system with more modern land management. Morphotype 2 (yellow) seemed to have consistent sporulation under both traditional and more modern land management systems. There are some factors that may influence sporulation of AM fungi including the fungi forming mycorrhiza, host plant and environmental factors such as soil properties and land management (Brundrett 1991; Sieverding 1991). The results found in this study could indicate that sporulation and dispersal ability between the fungi/morphotypes found are different. However, it would also be possible that the soil condition under maize cropping system managed with traditional and more modern land management systems may differently affect the ability of the fungi/morphotype to sporulate and to disperse. Since land management could affect the soil condition, particularly the soil physical and chemical properties, more studies must be set up to isolate the main 
factor that modulates the abundance and distribution of AM fungi at maize rhizosphere.

The result of this study may provide useful information on the impact of land management on distribution and community structure of AM fungi in semi-arid agricultural land. However, since AM fungal sporulation can be affected by many conditions, it is impossible to draw a general conclusion based on this study. Therefore, further studies need to be undertaken to deeply investigate other soil factors that might be impacted by various land management systems. Considering low morphotypes of AM fungi observed in this study, future studies need to be undertaken to combine both wet sieving and trapping culture methods to assess sporulation and diversity of AM fungi. Additionally, when it is possible, studies should investigate a molecular technique to detect sporulation and colonization of AM fungi. This may provide more information on AM fungal community between the two land management systems.

In conclusion, land management could affect the abundance and distribution of AM fungi, however many other factors might be also involved. Due to the important role of AM fungi for ecological functioning, more studies need to be undertaken to gain a better understanding of the effect of land management on AM fungi and on the interaction between AM fungi and their host. This may be helpful to develop methods for utilizing mycorrhizae in sustainable agriculture.

\section{ACKNOWLEDGEMENTS}

The study was funded by a grant from Directorate General of Higher Education, Ministry of Research, Technology and Higher Education of the Republic of Indonesia under the scheme of "Penelitian Unggulan Perguruan Tinggi Tahun 2015". The author appreciated Nusa Cendana University, Kupang, Indonesia, for facilitating the research.

\section{REFERENCES}

Bhadalung NaN, Suwanarit A, Dell B, Nopamornbodi O, Thamchaipenet A, Rungchuang R. 2005. Effects of long-term NP-fertilization on abundance and diversity of arbuscular mycorrhizal fungi under a maize cropping system. Plant Soil 270: 371-382.

Brundrett M, Bougher N, Dell B, Grove T, Malajczuk N. 1996. Working with Mycorrhiza in Forestry and Agriculture. Australian Centre for International Agricultural Research, Canberra, Australia.
Brundrett M. 1991. Mycorrhizas in natural ecosystems. Adv Ecol Res 21: 171-313.

de Oliveira AN, de Oliveira LA. 2010. Influence of edapho-climatic factors on the sporulation and colonization of arbuscular mycorrhizal fungi in two Amazonian native fruit species. Braz Arch Biol Techn 53: 653-661.

Entry JA, Rygiewicz PT, Watrid, LS, Donelly PK. 2002. Influence of adverse soil conditions on the formation and function of arbuscular mycorrhizas. Adv Environ Res 7: 123-138.

Ezawa T, Yamamoto K, Yoshida S. 2000. Species composition and spore density of indigenous vesicular-arbuscular mycorrhizal fungi under different conditions of P-fertility as revealed by soybean trap culture. Soil Sci Plant Nutr 46: 291-297.

Göhre V, Paszkowski EU. 2006. Contribution of the arbuscular mycorrhizal symbiosis to heavy metal phytoremediation. Planta 223: 1115-1122.

Ishaq L, Adu Tae ASJ, Airthur MA, Bako PO. 2017. Abundance of arbuscular mycorrhizal fungi associated with corn planted with traditional and more modern farming systems in Kupang, East Nusa Tenggara Timur. Biodiversitas 18: 887-892.

Jeffries S, Gianinnazi S, Perroto S, Turnau K, Barea JM. 2003. The Contribution of arbuscular mycorrhizal fungi in sustainable maintenance of plant health and soil fertility. Biol Fert Soils 37: 1-16

Kabir Z. 2005. Tillage or no tillage impact on mycorrhizal. Can J Plant Sci 85: 23-29.

Kaya C, Ashraf M, Sonmez O, Aydemir S, Tuna AL, Cullu MA. 2009. The influence of arbuscular mycorrhizal colonization on key growth parameters and fruit yield of pepper plants grown at high salinity Cengiz Kayaa. Sci Hort 121: 1-6.

Oehl F, Laczko E, Bogenrieder A, Sthar K Bosh R, van der Heijden M, Sieverding E. 2010. Soil type and land use intensity determine the composition of arbuscular mycorrhizal fungal communities. Soil Biol Biochem 42: 724-728.

Oehl F, Sieverding E, Ineichen K, Mader P, Boller T, Wiemkun A. 2003. Impact of land-use intensity on the species diversity of arbuscular mycorrhizal fungi in agroecosystems of Central Europe. Appl Environ Microbiol 69: 2816-2824.

Panwar V, Meghvansi M, Siddqui S. 2011. Short-term temporal variation in sporulation dynamics of arbuscular mycorrhizal (AM) fungi and physic-chemical edaphic properties of wheat rhizosphere. Saudi J Biol Sci 18: 247-258.

Porcel R, Ruiz-Lozano JM. 2004. Arbuscular mycorrhizal influence on leaf water potential, solute accumulation, and oxidative stress in soybean plants subjected to drought stress. J Exp Bot 55: 1743-1750.

Rubio R, Borie F, Schalchli C, Castillo C, Azcón R. 2003. Occurrence and effect of arbuscular mycorrhizal propagules in wheat as affected by the source and amount of phosphorus fertilizer and fungal inoculation. Appl Soil Ecol 23: 245-255.

Schalamuk S, Cabello M. 2010. Arbuscular mycorrhizal fungal propagule from tillage and no-tillage systems: possible effect on Glomeromycota diversity. Mycologia 102: 261-268.

Sieverding E.1991. Vesicular-Arbuscular Mycorrhiza Management in Tropical Agrosystems. Deutsche Gesselschaft fur Technische Zusammenarbeit (GTZ) GmbH, Eschborn, Federal Republic of Germany.

Smith SE, Read DJ. 2008. Mycorrhizal Symbiosis. Elsevier, New York, USA.

Song Y, Chen D, Lu K, Sun Z, Zeng R. 2015. Enhanced tomato disease resistance primed by arbuscular mycorrhizal fungus. Front Plant Sci 6: 786 . 